
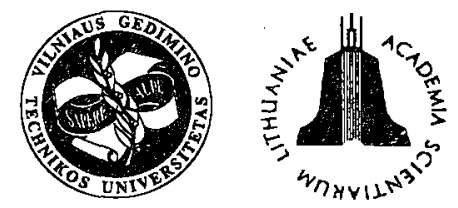

ISSN 1648-4142 TRANSPORT

http:/www.vtu.lt/english/editions

\title{
DYNAMICS OF A MOTOR VEHICLE TAKING INTO CONSIDERATION THE INTERACTION OF WHEELS AND ROAD PAVEMENT SURFACE
}

\author{
Olegas Prentkovskis ${ }^{1}$, Marijonas Bogdevičius ${ }^{2}$ \\ Department of Transport Technological Equipment, Vilnius Gediminas Technical University, \\ Plytines g. 27, LT-2016 Vilnius, Lithuania, Tel. (370 5) 2699705 \\ Received 200206 30; accepted 20021021
}

\begin{abstract}
The authors of this articie focus on the simulation of the motor vehicle on a certain road and propose their specific solution of this problem. A mathematical model of the system "motor vehicle - road" is presented. The motor vehicle is simulated by concentrated masses interconnected by elastic and dissipative links. The presented model of the motor vehicle evaluates the movement of the motor vehicle body in space; the movement and turning of front and rear suspensions with respect to the body; the interaction of the wheel with the road pavement surface; the blocking of the wheel; the changing cohesive forces which influence the motor vehicle. The investigated road pavement surface is simulated by triangular finite elements, the certain height of road pavement surface roughness and the cohesion coefficients of road pavement surface and the motor vehicle wheel in the longitudinal and transverse directions of the wheel are selected in each finite element nodal point. The presented results illustrate: the motor vehicle movement trajectories braking at various initial conditions and on a certain pavement surface of the road section under investigation and the motor vehicle driving on the speed reduction bump ("sleeping policeman").
\end{abstract}

Keywords: motor vehicle, dynamics, interaction, wheel, road pavement surface, mathematical simulation.

\section{Introduction}

A motor vehicle is the most comfortable and popular means of transport; however, it causes a lot of problems for all road users.

Accidents occur every 15 seconds, in which people suffer. One person is injured every 1.5 minute, i.e. one thousand people are injured in 24 hours. Thus, ca one million inhabitants of the Earth are lost in the period of three years [1].

The number of old cars exceeding its own resources several times has increased in Lithuania. Following statistics, one person is killed every 8 hours, and one person is injured each hour on Lithuanian roads [1].

Each year 4,000-6,000 registered road accidents occur in our country (the most typical are as follows: running over pedestrians, collision, overturning, hitting an obstacle, running over cyclists, hitting a parked vehicle) $[2,3]$.

The types of accidents vary. To study accidents of various types accurately, first of all, the universal dynamic model of the motor vehicle as well as the model of the road shall be constructed.

Simulation and description of the motor vehicle movement have been studied by scientists for several years.

\footnotetext{
'E-mail: olegas@ti.vtu.lt

22E-mail: marius@ti.vtu.lt
}

A. A. Chachaturov et al. studied the methods of road pavement description, suspension of automobiles, rolling of wheels and simulated the movement of the automobile [4].

A. Rutka and J. Sapragonas investigated the tyre and road interaction. Their scientific work analyzes the influence of the tyre on the road. The data of profile used in the investigation is measured on real roads. To investigate the smoothing function of tyres two models are used: flexible narrow ring $-2 D$ estimates the tyre and road contact in a line and flexible band - 3D estimates the dimensional contact between road and tyre [5].

S. J. DiMaggio and M. P. Bieniek investigated vehicle dynamics using limited surface treatment of the tyre - road interface. A new method of dealing with the forceproducing mechanism at the tyre - road interface is presented in their scientific work [6].

$\mathrm{J}$. Ambrósio created the vehicle dynamic model for frontal and oblique vehicle impact analysis. The multibody model of the vehicle is composed of 16 rigid bodies and nonlinear partially flexible body. The system components include a front double A-arm suspension system, a rear McPherson suspension system, wheels and chassis. A partially flexible body where the front part is considered flexible while the remaining structure and a shell is considered rigid. This modeling assumption is valid, if plastic deformations occur in the parts of the vehicle modeled 
as flexible regions such as the front and no significant deformation takes place in the passenger compartment. This model is suitable to simulate frontal impacts of the sports car. The flexible part of the chassis is composed of 36 nodal points and 38 nonlinear beam elements made of E24 steel and having hollow rectangular cross-section [7].

T. D. Williams, A. de Pennington and D. C. Barton investigated the impact behavior of low volume, niche market sports car with a spaceframe chassis using a nonlinear finite element. Considering the options to improve crash it was essential to make sure that the overall structural response is predicted. An experimental test programme supported the finite element predictions and included the impact testing of typical brazed tubular structures and an automotive wheel and tyre. Results from a 23,000 finite elements vehicle model correlate with the digitized results of a crash test video [8].

J. Giergiel and M. Śmieszek investigated automated guided vehicle movement along a curvilinear trajectory. Automated guided vehicles are widespread in modern manufacturing. The lowest speed of automated guided vehicles takes place during the movement along a curvilinear trajectory and results from necessities of assurance stability during movement. The authors decided to use the computer simulation process to explain this phenomena. During simulation the mathematical model of an automated guided vehicle was moving along curvilinear trajectory. Factors connected with the construction of an automated guided vehicle and with the trajectory were taken into account during simulation [9].

The dynamic models of motor vehicles presented by other scientists are very complicated and they can be simplified for simulating the movement of the motor vehicle on the road.

The authors of this article focus on the simulation of the motor vehicle on a certain road and propose their specific solution of this problem.

The movement of the motor vehicle on the road is a very complicated process which depends not only on the dynamic properties of the motor vehicle, but also on the conditions of the road section under investigation.

The system "motor vehicle - road" was selected for research. It consists of:

- a certain motor vehicle with known geometric parameters and physical mechanical properties (masses of individual elements, moments of inertia, size, stiffness coefficients, mechanical energy damping coefficients, etc.);

- a road section with known geometric parameters and physical mechanical properties (length, width, pavement surface, etc.).

To solve the constructed mathematical model of the system "motor vehicle - road" application packages Compaq Visual Fortran Professional v 6.1 [10] and Waterloo Maple $7.0[11,12]$ are used.
2. Mathematical Model of the Road Pavement Surface

To describe the road pavement surface roughness and cohesion coefficients of the road pavement and motor vehicle wheels on each nodal point of the road pavement surface the method of finite elements is applied $[2,3,13$, 14].

The total pavement surface of the road section is divided into triangular finite elements (FE) (Fig 1). A certain height of the road pavement surface roughness and cohesion coefficients of road pavement surface and motor vehicle wheels in the longitudinal and transverse directions of the motor vehicle wheels are selected in each nodal point of $\mathrm{FE}$.

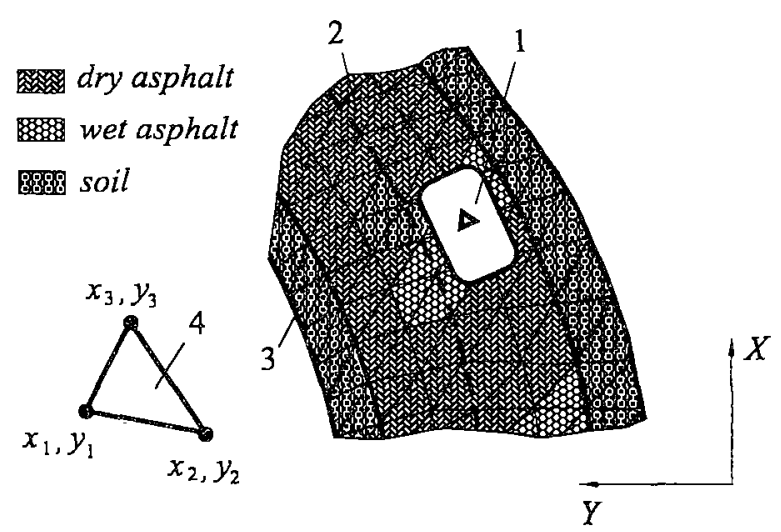

Fig 1. Expansion of the pavement surface of the road section into finite elements: 1 - motor vehicle; 2 - road carriageway; 3 - shoulder; 4 -triangular finite element

\section{Mathematical Model of the Motor Vehicle}

The motor vehicle is simulated by concentrated masses interconnected by elastic and dissipative links (Kelvin-Foight elements) [2, 3].

The motor vehicle model consists of seven concentrated masses: body, front and rear suspension and four wheels (Fig 2).

In the geometrical centre $O$ of the motor vehicle the system of coordinates $\zeta_{m v}-\eta_{n v}-\xi_{m v}$ is introduced and in the masses centre $C$ of the motor vehicle the system of coordinates $X_{m v}-Y_{m v}-Z_{m v}$ is introduced.

The masses centre $C$ of the motor vehicle is far from geometrical centre $O$ at distances $a_{x}, a_{y}, a_{z}$ in the directions of axes $\zeta_{m v}, \eta_{m v}, \xi_{m v}$. This discrepancy between motor vehicle masses and geometrical centre can be explained by the asymmetric distribution of passenger and load mass in the motor vehicle.

The body can move in space in the directions of global axis $X, Y$ and $Z$ and turn around local axes $X_{m v}$, $Y_{m v}, Z_{n v}$ of the motor vehicle. Front and rear suspensions can move in the direction of axis $Z_{m v}$ and turn on the vertical plane with respect to the body. Wheels can move in the direction of axis $Z_{n v v}$ with respect to the body. 
To describe the movement of the motor vehicle the following generalized coordinates are introduced (Fig 2):

$$
\begin{aligned}
& \left\{q_{m v}\right\}^{T}=\left[\begin{array}{llllll}
x_{C} & y_{C} & z_{C} & \varphi_{x_{C}} & \varphi_{y_{C}} & \varphi_{z_{C}}
\end{array}\right. \\
& \left.\begin{array}{llllllll}
z_{1} & \varphi_{1} & z_{2} & \varphi_{2} & z_{w 1} & z_{w 2} & z_{w 3} & z_{w 4}
\end{array}\right] .
\end{aligned}
$$
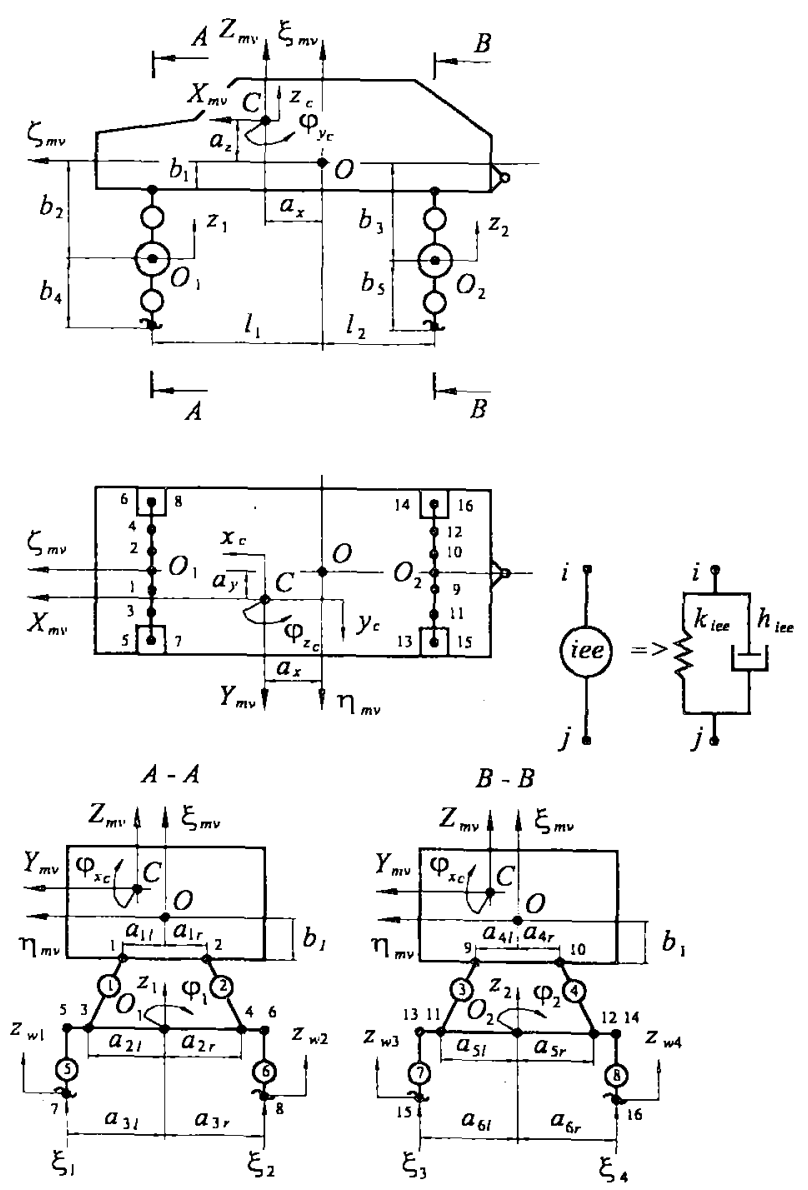

Fig 2. Motor vehicle model

The movement of the motor vehicle as the movement of an intricate mechanical system is described by second degree LaGrange equations:

$$
\frac{d}{d t}\left(\frac{\partial L}{\partial\left\{\dot{q}_{m \nu}\right\}}\right)-\frac{\partial L}{\partial\left\{q_{m \nu}\right\}}+\frac{\partial H}{\partial\left\{\dot{q}_{m v}\right\}}=\left\{F_{m \nu}\right\}
$$

where: $L$ - motor vehicle (mechanical system) LaGrange function,

$$
L=\mathrm{T}-\Pi \text {; }
$$

where: $T$ - kinetic energy of the motor vehicle; $\Pi$ potential energy of motor vehicle elastic elements; $\mathrm{H}$ dissipative function of motor vehicle dissipative elements; $\left\{q_{m v}\right\}$ - vector of generalized coordinates; $\left\{\dot{q}_{n\llcorner v}\right\}$-vector of generalized speeds; $\left\{F_{n v}\right\}$ - vector of generalized forces, influencing the motor vehicle.
Kinetic energy of the motor vehicle equals to:

$$
\begin{aligned}
& \mathrm{T}=\frac{1}{2}\left(m_{b}\left(\dot{x}_{C}^{2}+\dot{y}_{C}^{2}+\dot{z}_{C}^{2}\right)+I_{x_{C}} \dot{\varphi}_{x_{C}}^{2}+I_{y_{C}} \dot{\varphi}_{y_{C}}^{2}+\right. \\
& I_{z_{C}} \dot{\varphi}_{z_{C}}^{2}+m_{1} \dot{z}_{1}^{2}+I_{1} \dot{\varphi}_{1}^{2}+m_{2} \dot{z}_{2}^{2}+I_{2} \dot{\varphi}_{2}^{2}+ \\
& \left.m_{w 1} \dot{z}_{w 1}^{2}+m_{w 2} \dot{z}_{w 2}^{2}+m_{w 3} \dot{z}_{w 3}^{2}+m_{w 4} \dot{z}_{w 4}^{2}\right)
\end{aligned}
$$

where: $m_{b}$ - mass of the motor vehicle without front and rear suspensions (mass of the body); $m_{1}, m_{2}$ - masses of front and rear suspensions; $I_{x_{C}}, I_{y_{C}}, I_{z_{C}}$ - inertia moments of the motor vehicle (body) without front and rear suspensions around axis $X_{n v}, Y_{m v}, Z_{m v}, I_{1}, I_{2}$ inertia moments of front and rear suspensions around nodal points $O_{1}$ and $O_{2} ; m_{w 1}, m_{w 2}, m_{w 3}, m_{w 4}$ - masses of wheels.

Potential energy of elastic elements of the motor vehicle equals to:

$$
\Pi=\sum_{i e e=1}^{8} \Pi_{\text {iee }} ;
$$

where: $\Pi_{i e e}$ - potential energy of elastic element iee.

$$
\Pi_{i e e}=\frac{1}{2} k_{i e e} \Delta l_{i e e}^{2} ;
$$

where: $k_{i e e}$-stiffness coefficient of elastic element iee ; $\Delta l_{i e e}$ - contraction of elastic element iee .

$$
\Delta l_{\text {iee }}=l_{p \text { iee }}-l_{0 \text { iee }}
$$

where: $l_{p i e e}-$ present length of elastic element iee ; $l_{0}$ iee - initial length of elastic element iee .

\section{Let us consider that:}

$l_{p i e e}=\sqrt{\left(x_{j}-x_{i}\right)^{2}+\left(y_{j}-y_{i}\right)^{2}+\left(z_{j}-z_{i}\right)^{2}}=\sqrt{\Phi_{i e e}} ;$

where: $x_{i}, y_{i}, z_{i}$-global coordinates of the elastic element nodal point $i ; x_{j}, y_{j}, z_{j}$-global coordinates of elastic element nodal point $j ; \Phi_{i e e}$-function of elastic element iee .

Expressions (8) and (7) can be rewritten:

$$
\begin{aligned}
\Phi_{i e e} & =l_{p i e e}^{2} ; \\
\Delta l_{i e e} & =\sqrt{\Phi_{i e e}}-l_{0} \text { iee } .
\end{aligned}
$$

Then after evaluating expression (10), expression (6) can be rewritten as follows:

$$
\Pi_{i e e}=\frac{1}{2} k_{i e e} \Delta l_{i e e}^{2}=\frac{1}{2} k_{i e e}\left(\sqrt{\Phi_{i e e}}-l_{0} \text { iee }\right)^{2} .
$$

Derivative of potential energy according to the generalized coordinate $\left\{q_{n v}\right\}$ equals to: 


$$
\begin{aligned}
& \frac{\partial \Pi_{i e e}}{\partial\left\{q_{m \nu}\right\}}=k_{\text {iee }} \Delta l_{\text {iee }} \frac{\partial \Delta l_{\text {iee }}}{\partial \Phi_{\text {iee }}} \frac{\partial \Phi_{\text {iee }}}{\partial\left\{q_{m i v}\right\}}= \\
& \frac{1}{2} k_{\text {iee }}\left(1-\frac{l_{0 \text { iee }}}{\sqrt{\Phi_{\text {iee }}}}\right) \frac{\partial \Phi_{i e e}}{\partial\left\{q_{m v}\right\}} .
\end{aligned}
$$

Derivative of potential energy according to the generalized speed $\left\{\dot{q}_{n v}\right\}$ equals to:

$$
\frac{\partial \Pi_{i e e}}{\partial\left\{\dot{q}_{n v v}\right\}}=0
$$

Dissipative function of motor vehicle dissipative elements is equal to:

$$
\mathrm{H}=\sum_{\text {iee }=1}^{8} \mathrm{H}_{\text {iee }} \text {; }
$$

where: $\mathrm{H}_{\text {iee }}$ - dissipative function of elastic element

$$
\mathrm{H}_{\text {iee }}=\frac{1}{2} h_{i e e} \Delta \dot{l}_{\text {iee }}^{2} ;
$$

where: $h_{i e e}$-mechanical energy damping coefficient of elastic element iee; $\Delta i_{i e e}$ - contraction speed of elastic element iee .

$$
\begin{aligned}
& \Delta \dot{i}_{\text {iee }}=\frac{\partial}{\partial t} \Delta l_{\text {iee }}=\frac{\partial}{\partial t}\left(\sqrt{\Phi_{\text {iee }}}-l_{0} \text { iee }\right)= \\
& \frac{1}{2 \sqrt{\Phi_{\text {iee }}}} \frac{\partial \Phi_{\text {iee }}}{\partial\left\{q_{m v}\right.}\left\{\left\{\dot{q}_{m v}\right\} .\right.
\end{aligned}
$$

Having evaluated expression (16), expression (15) can be rewritten as follows:

$$
\begin{aligned}
& \mathrm{H}_{\text {iee }}=\frac{1}{2} h_{i e e} \Delta i_{i e e}^{2}= \\
& \frac{1}{2} h_{i e e}\left(\frac{1}{2 \sqrt{\Phi_{i e e}}} \frac{\partial \Phi_{i e e}}{\partial q_{m v}}\left\{\dot{g}_{m v}\right\}\right)^{2} .
\end{aligned}
$$

Derivative of dissipative function according to the generalized speed $\left\{\dot{q}_{m v}\right\}$ equals to:

$$
\frac{\partial \mathrm{H}_{\text {iee }}}{\partial\left\{\dot{q}_{m \nu}\right\}}=h_{\text {iee }} \frac{1}{2 \sqrt{\Phi_{\text {iee }}}} \frac{\partial \Phi_{\text {iee }}}{\partial\left\{q_{m \nu}\right\}}\left\{\dot{q}_{m \nu}\right\} .
$$

To find the expression of potential energy and dissipative function, global coordinates of every elastic element iee nodal points $i$ and $j$ shall be known. As it was mentioned the movement of the motor vehicle is investigated on a certain road section in the system of global coordinates $X-Y-Z$. The position of the motor vehicle in this global system of coordinates can be determined by generalized coordinates $x_{C}, y_{C}, z_{C}, \varphi_{x_{f}}, \varphi_{y_{C}}, \varphi_{z_{C}}$, $z_{1}, \varphi_{1}, z_{2}, \varphi_{2}, z_{w 1}, z_{w 2}, z_{w 3}, z_{w 4}$ of the motor ve- hicle. To find the position of any vehicle nodal point in the global system of coordinates $X-Y-Z$ local coordinates of the motor vehicle nodal point (rays from the motor vehicle masses centre to the investigated nodal point) and the coordinate transformation matrix (matrix, which determines turning of coordinates around axis $X_{m v}, Y_{m v}$, $Z_{m \nu}$ ) shall be known:

$$
[A]=\left[A_{Z_{m v}}\right]\left[A_{Y_{m v}}\right]\left[A_{X_{m v}}\right]
$$

where: $[A]$ - matrix of coordinate transformation; $\left[A_{Z_{m v}}\right],\left[A_{Y_{m v}}\right],\left[A_{X_{m v}}\right]$ - matrices of coordinate transformation around axes $Z_{n v}, Y_{m v}$ and $X_{m v}$.

The position of any motor vehicle nodal point in the global system of coordinates $X-Y-Z$ is determined by its global coordinate vector which is equal to:

$$
\left\{x_{k}\right\}=\left\{x_{C}\right\}+[A]\left\{x_{k} \text { loc }\right\} ;
$$

where: $\left\{x_{C}\right\}$-global coordinate vector of the motor vehicle masses centre; $[A]$ - matrix of coordinate transformation; $\left\{x_{k}\right.$ loc $\}$ - local coordinate vector of the motor vehicle nodal point $k ; k$ - any nodal point of the motor vehicle.

Functions $\Phi_{\text {iee }}$, iee $=1 \div 8$ of top and bottom elastic elements of suspension and derivatives $\frac{\partial \Phi_{i e e}}{\partial\left\{q_{n y}\right\}}$ of functions $\Phi_{i e e}$ according to generalized coordinate $\left\{q_{m v}\right\}$ are determined.

Provided functions $\Phi_{\text {iee }}$ of elastic elements of suspension and their derivatives according to the generalized coordinates $\frac{\partial \Phi_{i e e}}{\partial\left\{q_{m, n}\right\}}$ are known, potential energy $\Pi$ and dissipative function $\mathrm{H}$ of the motor vehicle can be determined.

Having inserted the expressions of the motor vehicle kinetic and potential energies, dissipative functions and the vector of generalized forces influencing the motor vehicle, into the second degree LaGrange equations (2), the system of the motor vehicle movement equation is obtained which can be written in the matrix form:

$$
\left[M_{m v}\right]\left\{\ddot{\theta}_{m v}\right\}=\left\{Q_{m v}\right\}
$$

where: $\left[M_{m \nu}\right]$ - matrix of motor vehicle masses; $\left\{\ddot{q}_{m \nu}\right\}$ vector of generalized accelerations; $\left\{Q_{m v}\right\}$-loading vector of the motor vehicle.

$$
\begin{aligned}
& {\left[M_{m v}\right]=\operatorname{diag}\left[\begin{array}{llllll}
m_{b} & m_{b} & m_{b} & I_{x_{C}} & I_{y_{C}} & I_{z_{C}}
\end{array}\right.} \\
& m_{1} \quad I_{1} \quad m_{2} \quad I_{2} \quad m_{w^{\prime} 1} \quad m_{w 2} \quad m_{w 3} \quad m_{w^{\prime} 4} \text {; }
\end{aligned}
$$




$$
\begin{aligned}
& \left\{\ddot{q}_{m \nu}\right\}=\left[\begin{array}{llllll}
\ddot{x}_{C} & \ddot{y}_{C} & \ddot{z}_{C} & \ddot{\varphi}_{x_{C}} & \ddot{\varphi}_{y_{C}} & \ddot{\varphi}_{z_{C}}
\end{array}\right. \\
& \left.\ddot{z}_{1} \quad \ddot{\varphi}_{1} \quad \ddot{z}_{2} \quad \ddot{\varphi}_{2} \quad \ddot{z}_{w 1} \quad \ddot{z}_{w 2} \quad \ddot{z}_{w 3} \quad \ddot{z}_{w 4}\right\rfloor \\
& \left.\left\{Q_{m \nu}\right\}=\left\{F_{m v}\right\}-\sum_{i e e=1}^{8} \frac{\partial \Pi_{\text {iee }}}{\partial\left\{q_{m \nu}\right\}}-\sum_{i e e=1}^{8} \frac{\partial H_{\text {iee }}}{\partial\left\{\dot{q}_{m v}\right.}\right\}
\end{aligned}
$$

where: $\left\{F_{m v}\right\}$-vector of generalized forces, influencing the motor vehicle,

$$
\begin{aligned}
& \left\{F_{m v}\right\}=\left[\begin{array}{llllll}
F_{x_{C}} & F_{y_{C}} & F_{z_{C}} & M_{x_{C}} & M_{y_{C}} & M_{z_{C}}
\end{array}\right. \\
& \left.\begin{array}{llllllll}
F_{1} & M_{1} & F_{2} & M_{2} & F_{w 1} & F_{w 2} & F_{w 3} & F_{w 4}
\end{array}\right]
\end{aligned}
$$

where: $F_{x_{C}}, F_{y_{C}}, F_{z_{C}}, F_{1}, F_{2}, F_{w 1}, F_{w 2}, F_{w 3}, F_{w \cdot 4}$, - generalized forces in the directions of respective generalized coordinates; $M_{x_{C}}, M_{y_{C}}, M_{z_{C}}, M_{1}, M_{2}^{-}$ generalized moments in the directions of respective generalized coordinates.

The system of equations (21) is solved by the method of Runge-Kutta [2, 3, 15]. For this purpose it has to be rearranged from 14 differential equations of the second order to 28 differential equations of the first order:

$$
\left\{\begin{array}{l}
\frac{d}{d t}\left\{q_{m v}\right\}=\left\{\dot{q}_{m v}\right\} \\
\frac{d}{d t}\left\{\dot{q}_{m v}\right\}=\left[M_{m v}\right]^{-1}\left\{Q_{n v}\right\}
\end{array}\right.
$$

\section{Conditions of the Contact of the Bottom Nodal Point of the Motor Vehicle Wheel and Road Pavement Sur- face}

Solving the system of equations (26) the contact between the motor vehicle wheel and road pavement surface has to be evaluated in every time step $[2,3]$.

The following conditions of contact between the motor vehicle wheel and road pavement surface are selected (Fig 3):

$$
\begin{gathered}
z_{w j}= \begin{cases}z_{w j j}, & \text { when } z_{w j} \geq \xi_{j} ; \\
\xi_{j}, & \text { when } z_{w j}<\xi_{j} ;\end{cases} \\
\dot{z}_{w j}=\left\{\begin{array}{cc}
\dot{z}_{w j}, & \text { when } z_{w j} \geq \xi_{j} \text { and } \dot{z}_{w j} \geq 0 ; \\
0, & \text { when } z_{w j}<\xi_{j} \text { and } \dot{z}_{w j}<0 ;
\end{array}\right. \\
\ddot{z}_{w j j}=\left\{\begin{array}{cc}
F_{e q j+10}, & \text { when } z_{w j} \geq \xi_{j} \text { and } F_{e q j+10} \geq 0 ; \\
0, & \text { when } z_{w j j}<\xi_{j} \text { and } F_{e q j+10}<0 ;(27)
\end{array}\right.
\end{gathered}
$$

where: $\xi_{j}$ - height of road pavement surface roughness under the motor vehicle wheels, $j=1 \div 4 ; F_{e q} j+10$ motor vehicle movement equations right side obtained with respect to $\dot{z}_{w j}$.

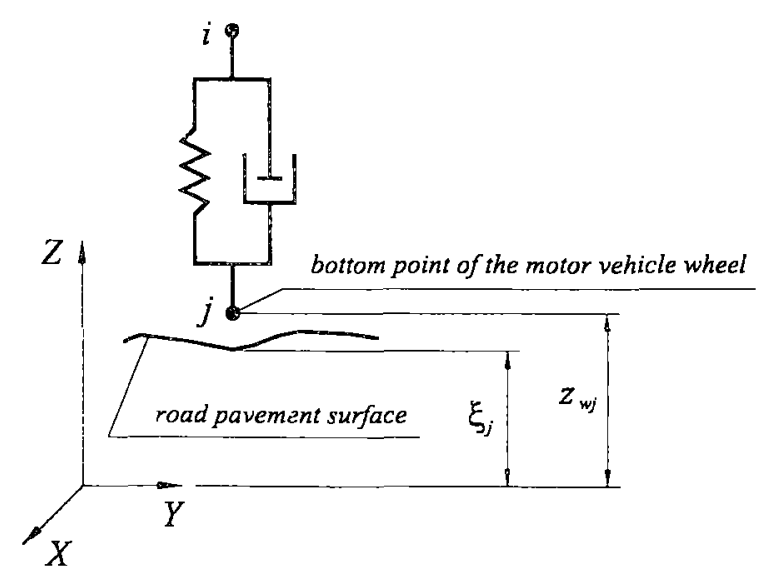

Fig 3. Identification circuit of the contact between motor vehicle wheel and road pavement surface

To find the height of road pavement surface under the motor vehicle wheel global coordinates of wheels in the system of coordinates $X-Y$ have to be known:

$$
\begin{aligned}
& x_{w i}=A_{11} r_{1 j}+A_{12} r_{2 j} ; \\
& y_{w j}=A_{21} r_{1 j}+A_{22} r_{2 j} ;
\end{aligned}
$$

where: $A_{11}, A_{12}, A_{21}, A_{22}$ - terms of coordinate transformation matrix $[A]$ (see expression (19)); $r_{1 j}$, $r_{2 j}$ - local rays from the motor vehicle masses centre to wheel $j, j=1 \div 4$.

When global coordinates of the wheels are known the dependence of a certain wheel on the exact finite element of the road pavement surface and the height of roughness of the road pavement surface under it can be determined.

\section{Identification of road pavement surface roughness and cohesion coefficients with the motor vehicle wheels}

The roughness of the surface on every nodal point $x, y$ of road finite element (Fig 1) are approximated as follows $[2,3]$ :

$$
\xi(x, y)=\left[\begin{array}{lll}
N_{1} & N_{2} & N_{3}
\end{array}\right]\left[\begin{array}{l}
\xi_{1} \\
\xi_{2} \\
\xi_{3}
\end{array}\right\}=[N(x, y)]\{\xi\}
$$

where: $\xi(x, y)$ - road pavement surface roughness on finite element hodal point $x, y ; N_{1}, N_{2}, N_{3}$ - shape 
functions of triangle finite element; $\xi_{1}, \xi_{2}, \xi_{3}$-surface roughness on finite element nodal points.

Let us consider that the cohesion coefficients of the motor vehicle wheel and road pavement surface are distributed according to the law of ellipsis (Fig 4) $[2,3]$ :

$$
\left(\frac{x_{w j}}{a}\right)^{2}+\left(\frac{y_{w j}}{b}\right)^{2}=1
$$

where: $x_{w j}, y_{w j}$ - cohesion coefficients on every nodal point of ellipsis; $a=\varphi_{\text {colhes }}^{\max }$ - maximum cohesion coefficient (in the longitudinal direction of the wheel); $b=\varphi_{\text {cohes }}^{\min }-$ minimum cohesion coefficient (in the transverse direction of the wheel).

In Fig 4 the distribution of the cohesion coefficient of wheel $j$ is presented: maximum cohesion coefficient - in the direction of axis $X_{w j}$, minimum - in the direction of axis $Y_{w j} \cdot X-Y$ - global system of coordinates, where movement of the motor vehicle is investigated; $X_{m v}-Y_{m v}-$ system of local coordinate of the motor vehicle, the beginning of this system of coordinates in the motor vehicle masses centre; $X_{w j}-Y_{w j}$-system of local coordinates of the wheel $j$, the beginning of the system of coordinates is in the motor vehicle wheel masses centre; $\varphi_{z_{C}}$ - angle between the systems of coordinates $X-Y$ and $X_{m v}-Y_{m v}$ (turning angle of the motor vehicle around the vertical axis, which crosses its masses centre); $\gamma_{w j}$-turning angle of wheel $j$ with respect to the motor vehicle body; $\left\{v_{w j}\right\}$ - sliding speed vector of wheel $j ; \chi_{w j}$-angle between axis $X_{w j}$ of wheel $j$ and sliding speed vector $\left\{v_{w j}\right\} ; \delta_{w j}$ - angle between the local axis $X_{m v}$ of the motor vehicle and sliding speed vector of the wheel $j$.

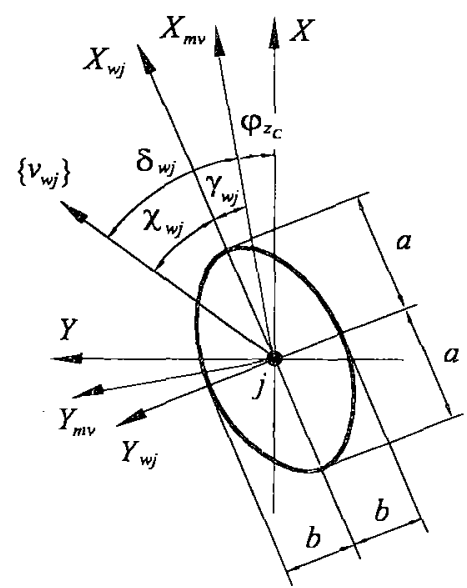

Fig 4. Distribution of the cohesion coefficient of wheel $j$
Equation (30) can be written parametrically:

$$
x_{w j}=a \cos \chi_{w j} ; y_{w j}=b \sin \chi_{w j} \text {. }
$$

Then dependence of cohesion coefficient on angle $\chi_{w j}$ equals to:

$$
\varphi_{\text {cohes }}\left(\chi_{w j}\right)=\sqrt{\left(a \cos \chi_{w j}\right)^{2}+\left(b \sin \chi_{w j}\right)^{2}} ;
$$

where: $\varphi_{\text {cohes }}\left(\chi_{w j}\right)$ - cohesion coefficient of wheel $j$ and road pavement surface in the direction of the wheel sliding speed $\left\{v_{w j}\right\}$.

$$
\chi_{w j}=\delta_{w j}-\gamma_{w j}
$$

where: $\gamma_{w j}$-turning angle of wheel $j$ with respect to the body of the motor vehicle anti-clockwise; $\delta_{w j}$ - angle between the local axis $X_{m v}$ of the motor vehicle and sliding speed vector $\left\{v_{w i j}\right\}$ of the wheel $j$,

$$
\delta_{w i j}=\operatorname{arctg}\left(\frac{v_{w j j y}}{v_{w j x_{m v}}}\right)
$$

where: $v_{w j x_{m v}}, v_{w j y_{m v}}$ - projections of the wheel sliding speed vector $\left\{v_{w j}\right\}$ to axes $X_{m w}$ and $Y_{m v}$ respectively;

Cohesion coefficients of the wheel and the road pavement surface on any finite element nodal point $x, y$ are approximated as follows:

$$
\begin{aligned}
& \varphi_{\text {cohes }}^{\max }(x, y)=[N(x, y)]\left\{\varphi_{\text {coles }}^{\max }\right\}=[N(x, y)]\{a\} ; \\
& \varphi_{\text {conhes }}^{\min }(x, y)=[N(x, y)]\left\{\varphi_{\text {cohes }}^{\min }\right\}=[N(x, y)]\{b\} ;
\end{aligned}
$$

where: $\varphi_{\text {colnes }}^{\max }(x, y), \varphi_{\text {cohes }}^{\min }(x, y)-$ maximum and minimum cohesion coefficients of the wheel and the road pavement surface on finite element nodal point $x, y$ : $[N(x, y)]$ - shape functions of triangle finite element; $\{a\},\{b\}$ - vectors of maximum and minimum cohesion coefficients on finite element nodal points. 
Road pavement surface roughness and cohesion coefficients of the wheel and the road pavement surface are divided linearly on the triangle finite element, therefore, the net of finite element shall be denser in the places where surface roughness or cohesion coefficients change rapidly (increase or decrease).

To perform fewer calculations it shall be estimated to which of the finite element each wheel belongs and height of road pavement surface roughness and cohesion coefficients of the each wheel and the road pavement surface are estimated only on four selected nodal points.

\section{Identification of Cohesive Forces}

Studying the movement of the motor vehicle motor vehicle wheel and road pavement surface cohesive forces cannot be neglected. Cohesive forces under different wheels can have different values depending on different cohesion coefficients of the vehicle wheels and road pavement surface $[2,3]$.

If the direction of the motor vehicle speed and wheel speed coincide and the wheel is not blocked (is not braked), cohesive force between the wheel and road pavement surface is equal to zero. Cohesive force will have certain value provided the directions of speeds mentioned above do not coincide or the wheel is not blocked (braking occurs).

When braking the motor vehicle or when it is sliding redistribution of the motor vehicle mass on the front and rear suspensions occurs which influences the movement of the motor vehicle. The more intensively the motor vehicle is braked, the greater part of the mass influences the front suspension and the front wheels are pressed harder (when the motor vehicle moves forward).

In general cohesive force which influences wheel $j$, equals to:

$$
F_{\text {cohesj }}=R_{z j} \varphi_{\text {cohesj }}
$$

where: $R_{z j}$ - normal reaction which influences road pavement surface; $\varphi_{\text {cohesj }}$ - cohesion coefficient of the motor vehicle wheel and road pavement surface which depends on the road pavement surface; $j=1 \div 4$.

Normal reaction which influences the road pavement surface is estimated as follows:

$$
R_{z j}=\left\{\begin{array}{c:c}
k_{j} \Delta l_{j}+h_{j} \Delta l_{j}, & \text { when } \Delta l_{j} \leq 0 \\
0, & \text { when } \Delta l_{j}>0
\end{array}\right.
$$

where: $k_{j}$-stiffness coefficient of suspension elastic element $j ; h_{j}$-mechanical energy damping coefficient of suspension elastic element $j ; \Delta l_{j}$ - contraction of suspension elastic element $j ; \Delta i_{j}$ - contraction speed of suspension elastic element $j$.

If $\Delta l_{j} \leq 0$, the motor vehicle wheel $j$ contacts with the road pavement surface; provided $\Delta l_{j}>0$, the motor vehicle wheel $j$ does not contact with the road pavement

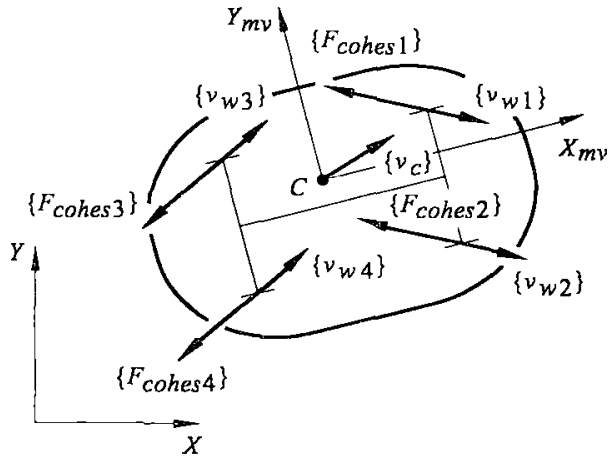

Fig 5. Cohesive forces which influence the motor vehicle wheels

surface.

Cohesive forces which influence the motor vehicle are shown in Fig 5.

Cohesive force which influences wheel $j$ is inserted in vector:

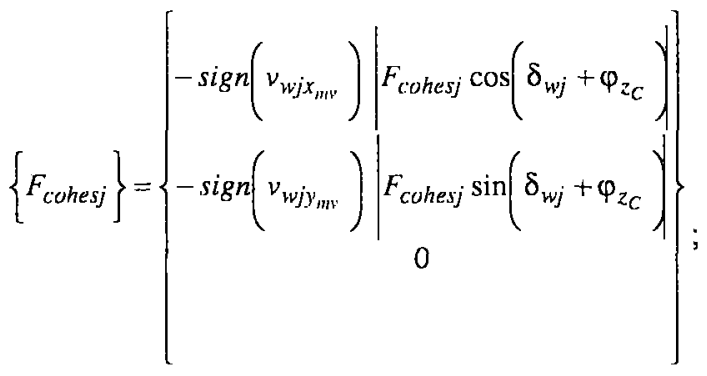

where: $v_{w j j x_{m w}} v_{w j y_{m v}}$-projections of motor vehicle wheel $j$ sliding speed vector $\left\{v_{w j}\right\}$ to local axes $X_{n v v}$ and $Y_{m v}$ of the motor vehicle respectively (see Fig 4); $\delta_{w j}$ angle between the local axis $X_{n \nu \nu}$ of the motor vehicle and sliding speed vector $\left\{v_{w j}\right\}$ of the wheel $j$ (see Fig 4 and expression (34)).

Cohesion moment of cohesive forces from wheel $j$ which influences the motor vehicle is equal to:

$$
\left\{M_{\text {cohesj }}\right\}=\left\{r_{c j}\right\} \times\left\{F_{\text {cohesj }}\right\}=\left[r_{c j}\right]\left\{F_{\text {cohesj }}\right\} \text {; }
$$

where: $\left\{r_{c j}\right\}$ - local vector from the masses centre of the motor vehicle to wheel $j ;\left[r_{c j}\right]$ - matrix of the motor vehicle wheel $j$.

General cohesive force vector which influences the motor vehicle and general cohesive moment are equal to:

$$
\begin{aligned}
& \left\{F_{\text {cohes }}^{g}\right\}=\sum_{j=1}^{4}\left\{F_{\text {cohesj }}\right\} ; \\
& \left\{M_{\text {cohes }}^{g}\right\}=\sum_{j=1}^{4}\left\{M_{\text {cohesj }}\right\} .
\end{aligned}
$$


General cohesive force vector $\left\{F_{\text {cohes }}^{g}\right\}$ which influence the motor vehicle and general cohesive moment $\left\{\begin{array}{l}M_{\text {cohes }}^{g} \\ \left\{F_{m,}\right\}\end{array}\right\}$ will be included to vector of generalized forces

7. Identification of Dependence of the Bottom Nodal Point of the Moter Vehiche Wheel Interacting with the Road Pavement Surface for Each Road Finite Element

As we have mentioned in Chapter 2 the road section under investigation is divided into triangular finite elements (FE). On each FE nodal point a certain height of the road pavement surface roughness and cohesion coefficients of road pavement surface and motor vehicle wheels in the longitudinal and transverse directions of the motor vehicle wheels are selected. Then the mentioned parameters can be calculated in each nodal point $x, y$ of FE applying the method of finite elements $[2,3]$.

To reduce the number of calculations it shall be estimated to which $\mathrm{FE}$ each of the motor vehicle wheels belongs.

It is only on these estimated four nodal points that the height of road pavement surface roughness as well as cohesion coefficients of the motor vehicle each wheel and road pavement surface are calculated (as we have mentioned in Chapter 5).

The position of a motor vehicle wheel on the road shall be expressed by the nodal point with coordinates $x_{w j}, y_{w j}$. Triangular FE containing this nodal point is estimated.

Nodal point $x_{w j}, y_{w j}$ belongs to triangle ife FE with nodal points $1,2,3$ provided condition:

$$
\left|S_{1,2,3}^{i f f}\right|=\left|S_{1,2, w j}^{i f e}\right|+\left|S_{2,3, w j}^{i f f e}\right|+\left|S_{3,1, w j}^{i f e}\right| \text { is met; }
$$

where: $S_{1,2,3}^{i f e}$-area of ife triangle $\mathrm{FE} ; S_{1,2, w j}^{i f f}, S_{2,3, w j}^{i f e}$, $S_{3, i, w j}^{i f e}$-areas of auxiliary triangles (Fig 6).

If coordinates of triangle vertices nodal points belong to the global system of coordinates $X-Y$, the area
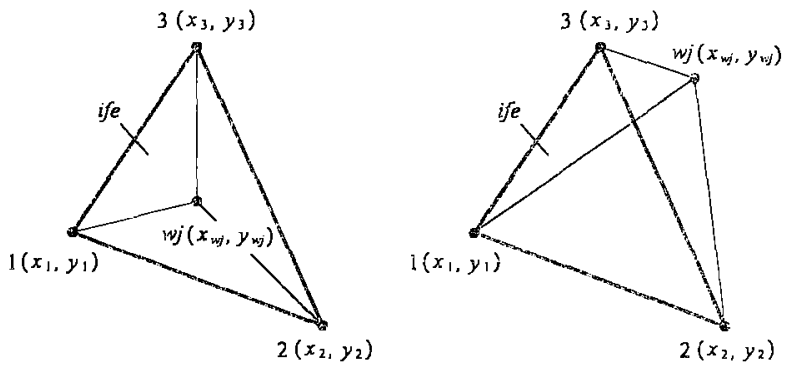

\footnotetext{
Fig 6. The identification circuit of nodal point $w j\left(x_{w j}, y_{w j}\right)$ dependence on ife triangle finite element: $a$ - nodal point belongs to a finite element; $b$-nodal point does not belong to a finite element
}

of triangles can be estimated $[2,3,15]$

$$
S_{1,2,3}^{i f e}=\frac{1}{2}\left|\begin{array}{lll}
1 & x_{1} & y_{1} \\
1 & x_{2} & y_{2} \\
1 & x_{3} & y_{3}
\end{array} ; \quad S_{1,2, w j}^{i f e}=\frac{1}{2} \begin{array}{ccc}
1 & x_{1} & y_{1} \\
1 & x_{2} & y_{2} \\
1 & x_{w j} & y_{w j}
\end{array}\right| ;
$$

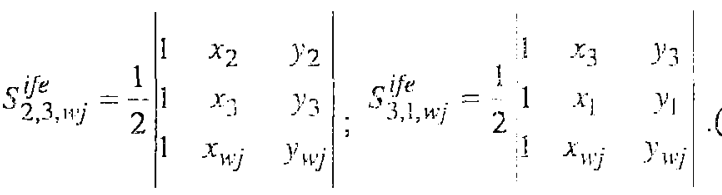

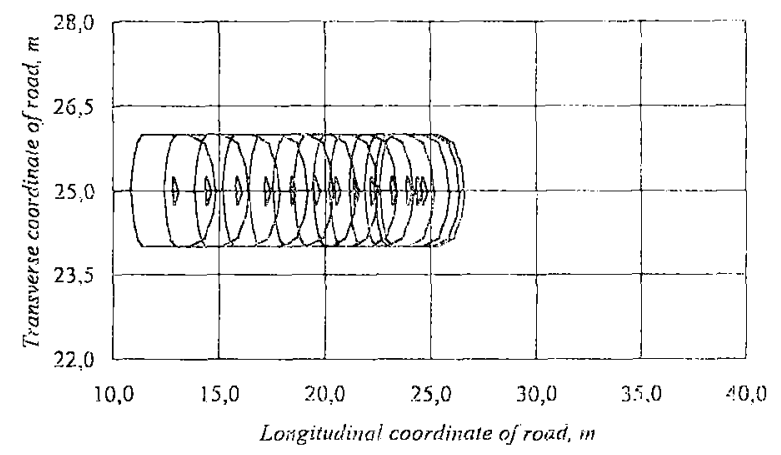

i)

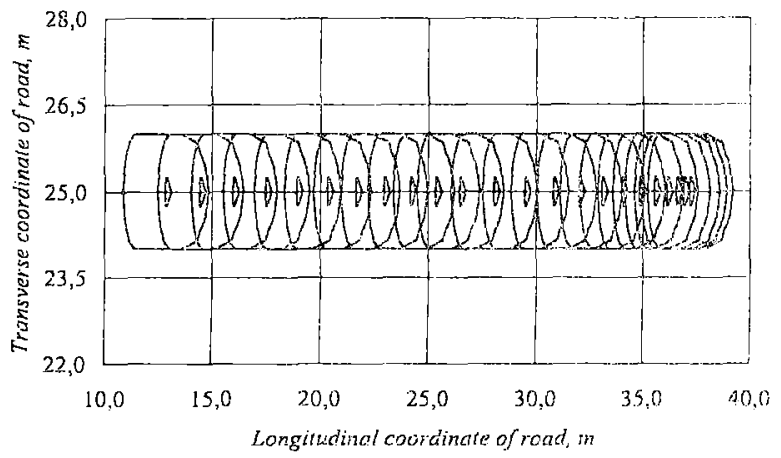

b)

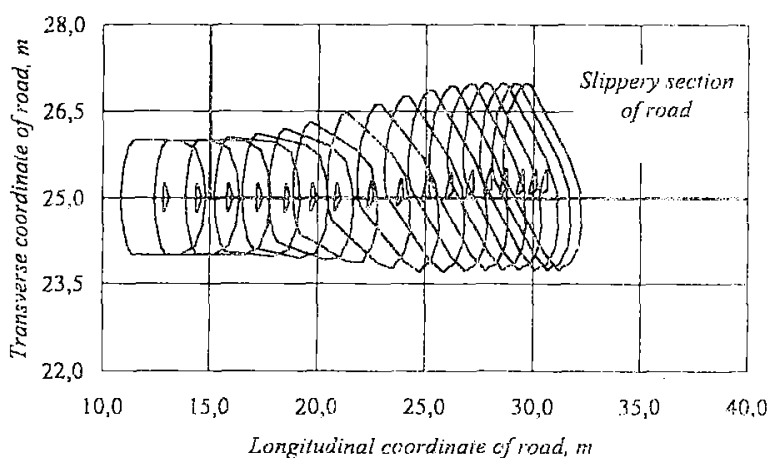

c)

Fig 7. Motor vehicle movement trajectories (view from top), the initial driving speed is $60 \mathrm{~km} / \mathrm{h}$ : a - road pavement is dry asphalt, braking all wheels; $b$-road pavement is dry asphait, braking two front or rear wheels; $c$ - when there is a slippery section on the road, braking all wheels 
If condition (41) is not met, nodal point $x_{w j}$, $y_{w j}$ does not belong to ife triangle FE.

\section{Results of a Computer Rxperiment}

To solve the dynamic model of the system "motor vehicle - road" the following results are obtained during the computer experiment using application packages Compaq Visual Fortran Professional v 6.1 [10] and Waterloo Maple $7.0[11,12]$ :

- the motor vehicle movement trajectories when braking at various initial conditions and a various certain pavement surface of the road section under investigation (Fig 7);

- the dependences of vertical displacement of motor vehicle wheel bottom nodal point on the longitudinal coordinate of the road when the motor vehicle drives on the speed reduction bump ("sleeping policeman") (Fig 8);

- the dependences of vertical acceleration of motor vehicle wheel bottom nodal point on the longitudinal coordinate of the road when the motor vehicle drives on the speed reduction bump ("sleeping policeman") (Fig 9);

- the dependences of normal reactions which influence road pavement surface on the longitudinal coordinate of the road when a motor vehicle drives on the speed reduction bump ("sleeping policeman") (Fig 10).

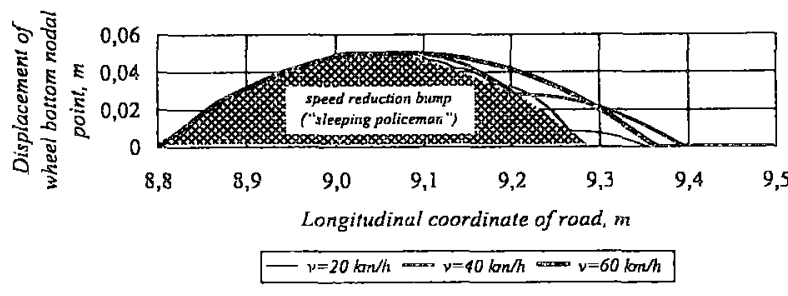

Fig 8. Dependence of the motor vehicle wheel bottom nodal point vertical displacement on the longitudinal coordinate of the road when the motor vehicle drives on the speed reduction bump ("sleeping policeman")

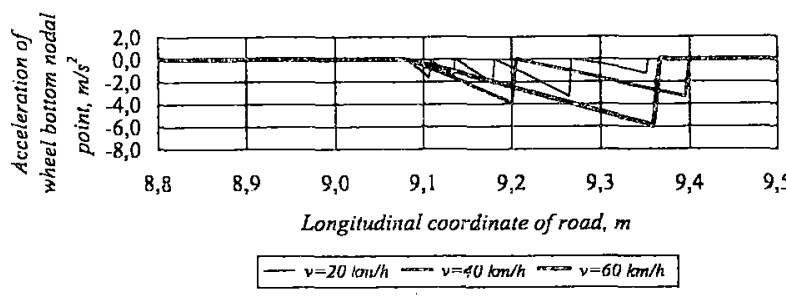

Fig 9. Dependence of the motor vehicle wheel bottom nodal point vertical acceleration on the longitudinal coordinate of the road, when the motor vehicle drives on the speed reduction bump ("sleeping policeman")

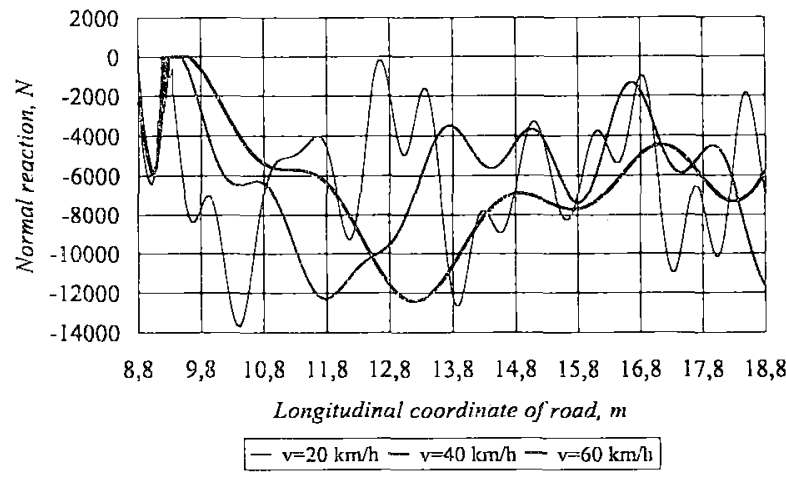

Fig 10. Dependence of the motor vehicle wheel normal reaction which influences road pavement surface on the longitudinal coordinate of road when the motor vehicle drives on the speed reduction bump ("sleeping policeman")

\section{Conclusions}

1. A mathematical model of the system "motor vehicle - road" is presented. It consists of the dynamic model of the motor vehicle and the model of the road section under investigation.

2. The motor vehicle is simulated by concentrated masses interconnected by elastic and dissipative links (Kelvin-Foight elements). The presented model evaluates the movement of the motor vehicle body in space; the movement and turning of front and rear suspensions with respect to the body; the interaction of the wheel with the road pavement surface; the blocking of the wheel; changing cohesive forces which influence the motor vehicle.

3 . The investigated road pavement surface is simulated by triangular finite elements, the certain height of road pavement surface roughness and cohesion coefficients of road pavement surface and the motor vehicle wheel in the longitudinal and transverse directions of the wheel are selected in each finite element nodal point.

4. Graphs in Fig $7 \mathrm{a}-\mathrm{b}$ illustrating the braking of the motor vehicle on the road, show that the less number of wheels of the motor vehicle brake (e.g., two or four), the longer the motor vehicle braking way is.

5. Graph in Fig $7 \mathrm{c}$ illustrating braking of the motor vehicle on the road shows that if there is a slippery section of road and all wheels of the motor vehicle are braked, the motor vehicle starts turning around its vertical axis passing through its masses centre when two wheels of the motor vehicle drive on the slippery section of road.

6. Graphs in Fig 8 - 10 illustrating the movement of the motor vehicle on the speed reduction bump ("sleeping policeman") show that if initial driving speed of a motor vehicle is less, the wheel will jump less on the speed reduction bump ("sleeping policeman"), and the wheel normal reaction as well as loading to the bearing part will be weaker. In other words, the speed shall be reduced when the motor vehicle is driving on the speed reduction bump ("sleeping policeman").

7. The presented mathematical model of the system 
"motor vehicle - road" as one part can be used simulating certain traffic scenarios (for example, to study the existing or to design new dangerous road sections; to study the interaction of the motor vehicle with various obstacles, etc).

\section{References}

1. Lukoševičienè $O$. The accidents analysis and simulation. Monograph (Autoivykių analizè ir modeliavimas. Monografija). Vilnius: Technika, 2001. 244 p (in Lithuanian).

2. Prentkovskis $\mathrm{O}$. Interaction between the Vehicle and $\mathrm{Ob}$ stacles: Doctoral Dissertation, Technological Sciences, Transport Engineering (Automobilio sąveika su kliūtimis: daktaro disertacija, technologijos mokslai, transporto inžinerija). Vilnius: VGTU, 2000117 p (in Lithuanian).

3. Prentkovskis $\mathrm{O}$. Interaction between the Vehicle and $\mathrm{Ob}-$ stacles: Summary of Doctoral Dissertation (Technological Sciences, Transports Engineering). Vilnius: Technika, 2000. $56 \mathrm{p}$.

4. Chachaturov A. A. et al. Dynamics of the System Road Tyre - Automobile - Driver (A. A. Хачатуров и др. Динамика системы дорога-шина-автомобиль-водитель). Moscow: Mashinostrojenije, 1975. 535 p (in Russian).

5. Rutka A.; Sapragonas J. The Role of a Tire in Vehicle and Road Interaction. Transport, Vol XVII, No 2, Vilnius: Technika, 2002, p 39-45.

6. DiMaggio S. J.; Bieniek M. P. Vehicle dynamics using a limit surface treatment of the tyre - road interface. Proceeding Instn Mech Engrs, Vol 212, Part D, 1998, p 347-356.

7. Ambrósio J. An Integrated Finite Element and Multibody Method for Frontal Oblique Vehicle Impact Analysis. European Conference on Computational Mechanics "ECCM
- 200I", June 26 - 29, 2001, Cracow, Poland (CD electronic form).

8. Williams T. D.; de Pennington A.; Barton D. C. The frontal Impact response of a Spaceframe Chassis Sportscar. Proceeding Instn Mech Engrs, Vol 214, Part D, 2000, p 865873.

9. Giergiel J.; Śmieszek M. Modeling of Automated Guided Vehicle Movement Along Curvilinear Trajectory. Collection of Scientific Works of Department of Applied Mechanics (Modelowanie ruchu automatycznie kierowanego pojazdu transportsowego na zakrźcie. Zeszyty naukowe katedry mechaniki stosowanej), No 15. Gliwice: Wydawnictwo Katedry Mechaniki Stosovwanej, 2001, p $101-$ 106 (in Polish).

10. Schick W.; Silverman G. Fortran 90 and Engineering Computation. John Wiley \& Sons, 1995. 425 p.

11. Aladjev V.; Bogdevicius M. Maple 6: Solution of Mathematical, Statistical and Engineering Physical Problems (B. Araдьев, М. Богдявичюс. Maple 6: Решение математических, статистических и инженерно-физических задач). Moscow: Laboratorija Bazovych Znanij, 2001. 824 p (in Russian).

12. Aladjev V;; Bogdevičius M.; Prentkovskis O. New Software for Mathematical Package Maple of Releases 6, 7 and 8. Monograph. Vilnius: Technika, 2002. 404 p.

13. Barauskas R. Fundamentals of a Finite Element Method (Baigtiniu elementu metodo pagrindai). Kaunas: Technologija, 1998. $376 \mathrm{p}$ (in Lithuanian).

14. Crisfield M. A. Non-linear Finite Element Analysis of Solid and Structures, Vol 1 - 2. John Wiley \& Sons, 1997.

15. Korn G.; Korn T. Reference Book on Mathematics for Scientific Workers and Engineers (Справочник по математике для научных работников и инженеров). Moscow: Nauka, 1968. 720 p (in Russian). 